\title{
LA LÓGICA OCULTA DE LA SELECCIÓN DE CANDIDATOS EN LAS ELECCIONES PARLAMENTARIAS CHILENAS*1
}

\author{
Peter Siavelis
}

¿Cómo ha afectado el sistema electoral binominal, impuesto durante el régimen de Pinochet, al proceso de selección de candidatos al Congreso? En lugar de partidos y coaliciones que buscan maximizar su votación, en este artículo se sostiene que una constelación engorrosa de variables incide en las decisiones sobre candidaturas y formación de las listas electorales en Chile. Se argumenta que el intento de alcanzar varios objetivos al mismo tiempo — relacionados con las alianzas de los subpactos, las coaliciones nacionales y las candidaturas presidenciales - se ha traducido a menudo en candidaturas parlamentarias que tal vez no contribuyen a maximizar la votación total individual o de lista. Es más, se advierte que los partidos pueden llegar a sacrificar algunos candidatos (y potencialmente, por tanto, escaños en el Congreso) con el fin de alcanzar esos objetivos discretos.

Peter Siavelis. Profesor Asociado de Ciencia Política y Hultquist Faculty Fellow en Wake Forest University. Es autor de The President and Congress in Postauthoritarian Chile: Institutional Constraints to Democratic Consolidation (Penn State Press, 2000), y de numerosos capítulos de libros y artículos en revistas profesionales. Su trabajo ha aparecido en Estudios Públicos, Comparative Politics y Comparative Political Studies. Su agenda de investigación actual se centra en el reclutamiento político y la selección de candidatos en América Latina. (E-mail: siavelpm@wfu.edu)

* Traducido al castellano por Alberto Ide.

${ }^{1}$ Ésta es una versión revisada y actualizada del artículo "The Hidden Logic of Candidate Selection for Chilean Parliamentary Elections", publicado en Comparative Politics 34: 2 (julio 2002), pp. 419-438. Quisiera agradecer los comentarios y sugerencias de Alejandro Foxley Tapia, Andrés Allamand y un árbitro anónimo de Estudios Públicos. 
Junto con plantear un conjunto de reglas que regirían las decisiones sobre las candidaturas parlamentarias en Chile, el autor destaca la importancia de analizar los efectos de los sistemas electorales y, en particular, de los sistemas estratégicamente complejos como el vigente en Chile, en los procesos de selección de candidatos en América Latina.

\section{L}

as consecuencias políticas del sistema electoral binominal ${ }^{2}$ aplicado en Chile para las elecciones parlamentarias han sido objeto de numerosos debates académicos y políticos. La mayoría de los análisis de la fórmula electoral han centrado la atención en sus consecuencias para el sistema de partidos $^{3}$ del país. Con todo, poco se ha escrito sobre la manera en que el sistema afecta a la selección de candidatos al parlamento y a la composición de las listas electorales en Chile.

El proceso de selección de candidatos es insuficientemente comprendido tanto por los chilenos como por quienes estudian la política chilena. En primer lugar, existe muy poco material escrito sobre los procesos internos de los partidos en Chile, o en Latinoamérica en general. En segundo lugar, hay un escaso nivel de consenso en cuanto a qué debemos medir y cómo hacerlo cuando analizamos el proceso de selección. La mayoría coincide en que dos aspectos centrales incluyen el grado de centralización y de participación popular ${ }^{4}$. La dificultad para medir estas variables y poner de manifiesto los que a menudo son procesos informales complica en gran medida la tarea de localizar el centro de control. En tercer lugar, la mayor parte de la bibliografía sobre el tema se concentra en los gobiernos parlamentarios europeos o en los Estados Unidos, y resulta menos aplicable a

${ }^{2}$ Las circunscripciones de dos miembros son poco comunes, aunque existen a nivel estadual en los Estados Unidos. Sus efectos mecánicos son analizados por Taagepera, Rein: "The Effect of District Magnitude and Properties of Two Seat Districts", 1984, pp. 1-102; y Cox, Gary: "Electoral Equilibrium in Double Member Districts", 1984, pp. 443-451.

${ }^{3}$ Las tendencias hacia la integración y la estabilización de los partidos que genera el sistema electoral son subrayadas, entre otros, por Guzmán, Eugenio: "Reflexiones sobre el Sistema Binominal”, 1993, pp. 303-325; y Rabkin, Rhoda: "Redemocratization, Electoral Engineering, and Party Strategies in Chile, 1989-1995”, 1996, pp. 335356. Entre aquellos que no están convencidos de que el sistema electoral posea estas cualidades se incluyen Siavelis, Peter y Arturo Valenzuela: "Electoral Engineering and Democratic Stability: The Legacy of Authoritarian Rule en Chile”, 1996, pp. 77-100; Valenzuela, J. Samuel y Timothy Scully: "Electoral Choices and the Party System en Chile: Continuities and Changes at the Recovery of Democracy", 1997, pp. 511-527; y Siavelis, Peter: "Continuity and Change in the Chilean Party System: On the Transformational Effects of Electoral Reform”, 1997, pp. 651-674.

4 Gallagher, Michael: “Introduction”, 1988, p. 4. 
los sistemas predominantemente multipartidistas y presidenciales de Latinoamérica.

Pese a estas importantes limitaciones, en el presente artículo se formulan algunas generalizaciones preliminares con respecto al proceso de selección de candidatos parlamentarios en Chile. Se comienza por describir el contexto de la reforma electoral y su vínculo con la selección de candidatos, y se continúa indicando algunos de los obstáculos que dificultan la comprensión del proceso en Chile. Luego el artículo explora los mecanismos reales de selección de candidatos para elecciones legislativas en tres niveles interrelacionados, aunque analíticamente distintos. Primero señala qué aspectos de los candidatos resultan atractivos para los partidos políticos, y analiza la manera en que éstos escogen a los aspirantes. Luego el artículo explora el fundamento lógico de las directivas de los partidos para formar pactos y subpactos, y analiza las variables más importantes que determinan a cuáles de los partidos que constituyen los subpactos se les adjudican candidaturas y en qué circunscripciones o distritos. La tercera sección examina los incentivos que influyen en la selección de candidatos al interior de las principales coaliciones, y la manera en que éstas definen la composición de las listas nacionales. Establece reglas de aplicabilidad general que rigen la selección de candidatos dentro de las coaliciones, y proporciona un diagrama esquemático de dichas reglas. En la última sección, para aportar evidencias que respalden estas reglas, se analiza empíricamente el proceso de selección de candidatos, subrayando algunas de las paradojas que se observan en él y que son producto de este singular sistema electoral.

El punto de partida para la mayoría de los análisis de elecciones es el hecho de que las colectividades políticas procuran maximizar el número de sufragios. El verdadero objetivo de los partidos y de las coaliciones es, por cierto, maximizar la cantidad total de escaños conseguidos en el parlamento, y por lo general la maximización de la votación y la maximización del número de asientos son exactamente la misma cosa. Sin embargo, en sistemas electorales estratégicamente complejos, como el chileno, estos supuestos aparentemente obvios dejan de funcionar, y el deseo de maximizar la cantidad total de escaños genera una constelación mucho más compleja de variables, las cuales determinan en cuál circunscripción se presentan los candidatos y con cuáles socios de coalición. Es más, los dirigentes intentan alcanzar una serie de objetivos, muchos de los cuales son contradictorios entre sí, y algunos no son examinados con especial cuidado en cuanto a sus consecuencias políticas. Maximizar el número de escaños es, por supuesto, el objetivo al que aspiran los partidos, pero a menudo los políticos tienen que conformarse con menos para así ocuparse de otros fines relacionados con 
las alianzas de los subpactos, las coaliciones nacionales y las candidaturas presidenciales. A decir verdad, los partidos pueden sacrificar cupos de candidatos (y por ende potenciales escaños) en favor de candidatos mucho menos populares, para de este modo mantener la integridad de la coalición. Los partidos pueden, asimismo, acordar abstenerse de competir en circunscripciones donde podrían ganar o presentar un mejor candidato, en aras de la unidad de la coalición, o para obtener candidaturas en otras circunscripciones más competitivas. La interacción que se produce entre las diversas series de grupos, subgrupos y dirigentes individuales al afrontar simultáneamente los desafíos que surgen en todos estos niveles es lo que determina quién compite dónde, y en qué circunstancias, en las elecciones parlamentarias chilenas.

\section{Democratización e ingeniería electoral en Chile}

Durante la mayor parte de su historia democrática Chile empleó en las elecciones para la Cámara de Diputados y el Senado un sistema permisivo de representación proporcional, con distritos multinominales. Tras un interregno de casi 17 años de régimen autoritario encabezado por el general Augusto Pinochet, las autoridades militares impusieron una serie de cambios constitucionales y electorales. Estas reformas tenían por objeto transformar el sistema de partidos, en un esfuerzo por corregir lo que las autoridades castrenses percibían como la malsana naturaleza de la competencia polarizada e ideológica entre partidos durante la larga experiencia democrática del país. La más importante de estas reformas fue la adopción de una fórmula electoral con circunscripciones de dos miembros, también conocida como sistema binominal. La fórmula electoral fue concebida para mitigar las consecuencias negativas del a menudo turbulento e ideologizado sistema de partidos, y para proporcionar una ventaja a los partidos de la derecha $^{5}$. Los reformadores esperaban que con el tiempo el sistema erradicara a la izquierda al marginarla de la política electoral.

Los reformadores castrenses supusieron que una reducción en la magnitud de las circunscripciones conduciría a una integración del sistema de partidos y a una disminución en la cantidad de los mismos. Basándose en supuestos planteados por obras teóricas en cuanto al efecto reductor de los sistemas con circunscripciones de pequeña magnitud, ellos esperaban que la fórmula electoral permitiera por lo menos llegar a consolidar un multi-

${ }^{5}$ Véase Siavelis y Valenzuela: "Electoral Engineering and Democratic Stability: The Legacy of Authoritarian Rule in Chile”, 1996. 
partidismo moderado, y en el mejor de los casos a formar un sistema bipartidista $^{6}$.

La ley electoral binominal dispone que cada partido o alianza electoral del país pueda presentar dos candidatos a las elecciones para la Cámara de Diputados en cada una de las 60 circunscripciones del país. El sistema binominal se emplea también en las elecciones para el Senado, en cada una de las 19 circunscripciones senatoriales. Los votantes escogen un solo candidato entre una serie de listas abiertas de 2 candidatos. El aspirante que reúna la mayoría simple de votos obtiene el primer escaño en cada circunscripción, aunque en la práctica es improbable que su coalición consiga el segundo escaño. Dadas las características de funcionamiento del sistema de representación proporcional D’Hondt en circunscripciones binominales, para que un partido o coalición se quede con ambos escaños tiene que duplicar la votación de la lista competidora que más se le aproxime. A fin de disipar cualquier duda acerca de esta dinámica de funcionamiento, la ley orgánica constitucional que regula las elecciones estipula, en efecto, que para ganar dos escaños una lista debe duplicar la votación de su competidor más cercano.

Un ejemplo concreto sirve para aclarar esta descripción del sistema, y para señalar algunas de sus consecuencias más contrarias a la intuición. En la Tabla $\mathrm{N}^{\circ} 1$ aparecen los resultados de la elección parlamentaria de 1989 correspondientes a la 19ª circunscripción. Puede apreciarse que si bien ambos candidatos de la Concertación obtuvieron individualmente más votos y un mayor porcentaje de la votación que cualquiera de los aspirantes de la coalición Democracia y Progreso (actual Alianza por Chile), las normas del sistema electoral estipulaban que los ganadores de esta carrera eran Mario Hamuy y Cristián Leay. Ello ocurrió porque la lista de la Concertación no logró duplicar la votación total de la lista de Democracia y Progreso.

Así pues, el sistema electoral establece determinados umbrales. En cada circunscripción, para conseguir un escaño es preciso que un partido o coalición alcance por lo menos el 33,4\% de la votación, y para conquistar ambos escaños debe recibir el $66,7 \%$ de dicha votación. Aun cuando muchos han señalado la importancia de este umbral efectivo de $66,7 \%$ y $33,4 \%$ para ganar dos y un escaño, respectivamente, en cada circunscripción la

${ }^{6}$ Los reformadores recurrieron a la hipótesis del votante medio de Downs como la lógica que generaría la competencia centrípeta y bipolar entre los partidos en Chile. Sin embargo, como lo demuestran Magar y otros, Downs basó su análisis en circunscripciones de un solo miembro, y la dinámica bipolar producida por magnitudes de dos difiere de la explorada por Downs y puede incluso fomentar la competencia centrífuga. Véase Downs, Anthony: An Economic Theory of Democracy, 1957, y Magar, Eric, Marc Rosenblum y David Samuels: "On the Absence of Centripetal Incentives in Double Member Districts: The Case of Chile”, 1998, pp. 714-739. 
TABLA N ${ }^{\circ}$ 1: $\quad$ RESULTADOS ELECTORALES DE LA $19^{\mathrm{a}}$ CIRCUNSCRIPCIÓN RECOLETA, REGIÓN METROPOLITANA DE SANTIAGO

\begin{tabular}{lcc}
\hline Coalición & Votos & Porcentaje* \\
\hline Concertación: & & \\
Mario Hamuy (PDC) & 41.876 & 34,0 \\
Óscar Santelices (PPD) & 39.549 & 32,1 \\
Total & 81.425 & 66,1 \\
Democracia y Progreso: & & \\
Cristián Leay (UDI) & 34.137 & 27,7 \\
Mauricio Smok (RN) & 7.647 & 6,2 \\
Total & 41.784 & 33,9 \\
\hline
\end{tabular}

* Esta cifra representa el porcentaje de la votación obtenido por las dos principales coaliciones. Hubo, por cierto, otros partidos y listas pequeños, pero los datos se presentan de esta manera para dejar en claro la importancia de los umbrales para los dos partidos más poderosos.

Fuente: Ministerio del Interior, sitio “Elecciones históricas”, http://www. elecciones.gov.cl/

capacidad de ganar escaños depende, por cierto, también de la distribución de los votos y del número de listas que compitan en todas las circunscripciones. En esencia, el umbral de representación en cada circunscripción es una función que varía según la cantidad de listas que presentan candidatos y sus niveles relativos de apoyo. Por ejemplo, en caso de que haya muchas listas en competencia, si la primera lista electoral recibe una mayoría simple de $22 \%$ de la votación, conseguirá un escaño, y la lista con la segunda votación más alta sólo necesita recibir el 11\% más uno de los sufragios para hacerse con el segundo escaño.

No obstante, los reformadores estaban conscientes de la probable fisonomía de la competencia posautoritaria entre partidos, y concibieron el sistema teniendo en mente una modalidad de dos listas. Las razones y los factores que condujeron al establecimiento de un sistema binominal son aún materia de debate. Muchos sostienen que fue consecuencia directa de los resultados del plebiscito, y que los reformadores del gobierno militar lo diseñaron sabiendo que la oposición de centro-izquierda tendría dificultades para reunir el 66,7\% de la votación en todas las circunscripciones a nivel nacional, cifra necesaria para conseguir más de un escaño en cada una de las circunscripciones en las elecciones posteriores al régimen autoritario. 
Otros estiman que la trayectoria del sistema binominal es más larga, que la decisión de adoptarlo fue más compleja, y que el cálculo político inmediato no desempeñó un papel tan importante como algunos sugieren. Y agregan que los debates iniciales en torno a la conveniencia del sistema binominal estuvieron inspirados más bien por el patrón histórico de Chile de competencia entre partidos, y específicamente por el desempeño electoral tradicionalmente deslucido de la derecha. Como lo señala Pastor, ya en 1984 se debatía sobre la posibilidad de adoptar un sistema binominal ${ }^{7}$. Aun así, lo cierto es que los detalles y la fórmula del sistema binominal, y en particular el requisito de que una lista duplicara la votación total de la segunda lista, fueron promulgados como artículo 109 bis de la Ley Orgánica 18.700, más de un año después de la derrota de Pinochet en el plebiscito. Por tanto, si bien puede resultar exagerado afirmar que la totalidad del diseño del sistema fue una reacción de pánico frente al revés en el plebiscito, es innegable que los resultados del mismo influyeron hasta cierto punto en la estructura final del sistema. En consecuencia, los reformadores del gobierno militar pudieron usar información basada en sondeos de opinión pública y en los resultados del plebiscito de 1988, por lo que efectivamente sabían que la derecha probablemente obtendría entre el $35 \%$ y el $40 \%$ de la votación. La fórmula electoral permitiría, por ende, que la derecha, con poco más del 33\% de la votación, consiguiera uno de los dos escaños en cada circunscripción (o el $50 \%$ de los escaños).

La realidad de esos umbrales electorales tan altos crea asimismo una interesante dinámica en cuanto a los incentivos que moldean el proceso de formación de listas parlamentarias y la competencia electoral, fenómenos que son analizados a fondo más adelante. En pocas palabras: dado el elevado umbral necesario para ganar dos escaños, compartir una lista con un candidato relativamente más poderoso en una circunscripción donde puede esperarse que la coalición consiga una votación inferior al 66,7\% es una fórmula segura para sufrir una derrota. Es así como los candidatos tienen un aliciente para tratar de formar duplas con compañeros de coalición más débiles (o sea, que les permita alcanzar el umbral de 33,4\% necesario para obtener el escaño, imponiéndose sobre su compañero de lista), o con compañeros extremadamente poderosos para así permitir que la lista electoral llegue a doblar (es decir ganar ambos escaños en la circunscripción al cruzar el umbral de 66,7\%). Los umbrales del sistema también inciden en las decisiones estratégicas de la coalición minoritaria. La coalición mayoritaria emprende una estrategia para intentar doblar en tantas circunscripciones como

${ }^{7}$ Pastor, Daniel: “Origins of the Chilean Binominal Electoral System”, 2004, pp. 38-57. 
sea posible, mientras que la coalición minoritaria procura evitar que la coalición mayoritaria llegue a doblar.

¿Cuál ha sido el efecto del sistema electoral en el sistema de partidos? ¿Se ha transformado radicalmente la competencia entre partidos? Desde el retorno a la democracia la política de partidos ha estado dominada por dos coaliciones multipartidistas: la centroizquierdista Concertación de Partidos por la Democracia (la Concertación), y la centroderechista Alianza por $\mathrm{Chile}^{8}$. Este patrón de competencia bipolar entre coaliciones no tiene precedentes en cuanto a la durabilidad y poder de estas alianzas políticas. Los defensores del sistema binominal argumentan que éste ha fomentado la competencia centrípeta, la negociación y la integración del sistema de parti$\operatorname{dos}^{9}$, pero tal vez están incurriendo en una exageración. Los dirigentes de los partidos han empleado estrategias para contrarrestar la característica de la fórmula electoral que tiende a reducir los partidos, y el sistema de partidos presenta sorprendentes semejanzas con su equivalente multipartidista del período preautoritario. El grueso de las evidencias sugiere que pese a existir dos amplias coaliciones, al igual que en el período preautoritario hay hoy en día 4 ó 5 partidos políticos relevantes, ninguno de los cuales puede arrogarse la mayoría ${ }^{10}$.

Así pues, la existencia continuada de un sistema multipartidista profundamente arraigado está reñida con las características mayoritarias del sistema electoral. En cada circunscripción pueden presentarse sólo dos candidatos de cualquiera de las dos grandes coaliciones (las cuales es preciso formar para que un partido pueda lograr buenos resultados). Al mismo tiempo aún existen cuatro o cinco grandes partidos y diversos partidos menores. Los dirigentes de esas colectividades se ven obligados a entablar complejas y prolongadas negociaciones para elaborar listas parlamentarias con dos candidatos. Si bien la selección de candidatos constituye efectivamente un proceso de toma de decisiones consensuadas, de formación de coaliciones y de negociación, también hay un elemento de presión e inflexibilidad dado el limitado número de recompensas por participar en la coalición y la reducida cantidad de incentivos (escaños) con los cuales negociar.

${ }^{8}$ Esta alianza también ha sido conocida como "Democracia y Progreso", "Unión por el Progreso de Chile” y "Unión por Chile”. Véase Figura 1.

9 Guzmán: "Reflexiones sobre el Sistema Binominal”, 1993, y Rabkin, Rhoda: "Redemocratization, Electoral Engineering, and Party Strategies in Chile, 1989-1995", 1996.

${ }^{10}$ Siavelis y Arturo Valenzuela: "Electoral Engineering and Democratic Stability: The Legacy of Authoritarian Rule in Chile”, 1996; Valenzuela, J. Samuel y Timothy Scully: "Electoral Choices and the Party System in Chile: Continuities and Changes at the Recovery of Democracy", 1997, y Siavelis, Peter: "Continuity and Change in the Chilean Party System: On the Transformational Effects of Electoral Reform”, 1997. 
El que estas negociaciones hayan prosperado en las últimas cuatro elecciones parlamentarias (1989, 1993, 1997 y 2001) es un testimonio de la tenacidad del sistema de partidos del país y de la capacidad de negociación de los dirigentes políticos chilenos. ¿De qué manera se han transformado los procesos de selección de candidatos y de formación de coaliciones para acomodar al sistema de partidos dentro de la actual fórmula electoral mayoritaria?

\section{Factores que entorpecen la comprensión del proceso de selección de candidatos al Congreso en Chile}

Antes de analizar el proceso y los incentivos reales que están detrás de la selección de candidatos en Chile es importante exponer algunos de los factores que impiden comprender cabalmente el proceso de composición de listas. En primer lugar, durante las últimas cuatro elecciones parlamentarias la continuidad de varios importantes partidos políticos y de una serie de colectividades menores ha complicado el proceso de designación de candidatos en términos numéricos. Aunque los partidos se han aliado en dos grandes coaliciones, al interior de ellas existen además diversos "subpactos” que representan distintas tendencias ideológicas. Los subpactos, cuya composición se examina a continuación, están agrupados en torno a grandes partidos "ancla".

Estos subpactos plantean exigencias a sus coaliciones. De manera que cuando se elaboran listas de candidatos a nivel nacional los partidos deben negociar para garantizar que exista equidad en la distribución de los cupos entre los diversos partidos y subpactos que componen cada coalición. La Figura $\mathrm{N}^{0} 1$ proporciona un desglose de la composición de las coaliciones, los subpactos y sus partidos para las elecciones de 1989, 1993, 1997 y 2001, además de las siglas para identificar los partidos, las cuales facilitan la comprensión del análisis posterior.

Cada uno de estos partidos cuenta con su propio proceso para designar candidatos. Pero si bien cada partido puede tener un contingente completo de 120 candidatos, ya que cada alianza nacional está limitada a esta cantidad, a cada candidato le queda un largo y arduo camino por recorrer desde el momento en que recibe el apoyo del partido hasta que efectivamente ve su nombre inscrito en la papeleta de votación.

En segundo lugar, el proceso de selección de candidatos ha variado en cada una de las cuatro elecciones parlamentarias que se han celebrado desde el retorno a la democracia. En muchos casos el proceso ha tendido a 
FIGURA N $\mathrm{N}^{\circ}$ 1: $\quad$ COALICIONES, SUBPACTOS Y PARTIDOS EN LAS ELECCIONES PARLAMENTARIAS CHILENAS DE 1989, 1993, 1997 Y 2001

\begin{tabular}{|c|c|c|}
\hline & Centro-izquierda & Centro-derecha \\
\hline & 1989 & 1989 \\
\hline Coalición & $\begin{array}{ll}\downarrow \\
\stackrel{P D C}{\text { Concertación }}\end{array}$ & $\underset{\text { IND }}{\downarrow}$ \\
\hline & 1993 & 1993 \\
\hline $\begin{array}{l}\text { Coalición } \\
\text { Subpactos }\end{array}$ & $\begin{array}{l}\swarrow \\
\text { PDC } \\
\downarrow\end{array}$ & 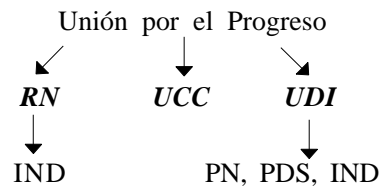 \\
\hline & 1997 & 1997 \\
\hline $\begin{array}{l}\text { Coalición } \\
\text { Subpactos }\end{array}$ & PRSD, IND & 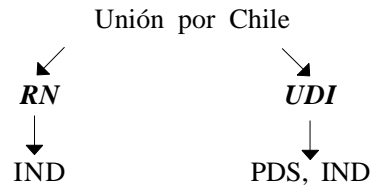 \\
\hline & 2001 & 2001 \\
\hline Coalición & $\underset{\text { IND }}{\checkmark}$ & 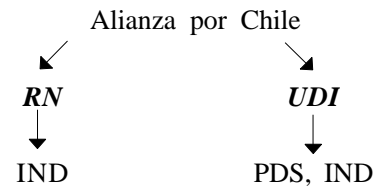 \\
\hline
\end{tabular}

Siglas de los partidos:

IC: Izquierda Cristiana.

PN: Partido Nacional.

IND: Independientes asociados con subpactos. PR: Partido Radical.

PAC: Partido Alianza de Centro. PV: Partido Verde.

PDC: Partido Demócrata Cristiano,

SD: Social Democracia.

PDI: Partido Democrático de Izquierda.

RN: Renovación Nacional.

PH: Partido Humanista.

PRSD: Partido Radical Socialdemócrata.

PDS: Partido del Sur.

UCC: Unión de Centro Centro.

* Partidos ancla en negritas-cursiva.

UDI: Unión Demócrata Independiente. 
la apertura y la democratización, con la introducción de cierto tipo de elección primaria en algunos de los partidos. Aun así, como se señalará en la conclusión, la complejidad del proceso de formación de coaliciones milita en contra de dicha apertura, y la selección de candidatos continúa siendo principalmente un asunto de las directivas.

Por último, la composición de las listas electorales ha estado profundamente influida por el proceso de transición, y ella misma está en transición. Teniendo en cuenta el predominio de las elites de los partidos cuando se escogían los candidatos durante la era preautoritaria, la cuestión de la democratización de las estructuras internas de los partidos volvió a plantearse con el retorno a la política democrática. Más de 16 años de régimen autoritario significaron también que durante la etapa previa a la primera elección había pocas mediciones recientes y concretas del verdadero nivel de apoyo con que contaban los partidos. Los partidos disponían de escasos datos fidedignos que pudieran emplear como herramienta de influencia en el proceso de negociación. Con el acceso a más información en las recientes elecciones, los mecanismos para designar a los candidatos han adquirido una estructura más formalizada.

En vista de estas realidades, resulta difícil establecer con precisión reglas concretas, pues ellas aún tienen que ser formuladas. La expresión chilena "en el camino se arregla la carga” es la que tal vez mejor describe los cambios introducidos en el proceso que regula la selección de candidatos y la composición de las listas electorales. Cuando encaran cuestionamientos y presiones para una mayor democratización, o cuando han surgido amenazas a la mantención de la coalición, los partidos han modificado los procesos de selección de candidatos.

No obstante estas dificultades, es posible analizar en términos generales los desafíos con que se enfrenta cada una de las dos coaliciones chilenas cuando se trata de compatibilizar las exigencias de sus partidos integrantes para armar dos listas de candidatos en 60 circunscripciones cada cuatro años ${ }^{11}$.

\section{La composición de las listas electorales}

En términos muy simples, el objetivo de todo candidato en una elección es maximizar el número de votos. De lo anterior se desprende que las coaliciones deben tratar de escoger a los dos candidatos capaces de reunir

${ }^{11}$ Mientras otras listas electorales presentan candidatos, estas dos en conjunto han reunido más del $80 \%$ de la votación en todas las elecciones parlamentarias de la era posautoritaria. 
la mayor cantidad total de votos en una determinada circunscripción. Ahora bien, los pactos y subpactos de cada coalición también tienen objetivos distintos de los de los candidatos individuales, y en particular procuran maximizar su número total de escaños en el parlamento. Importantes funcionarios en las esferas de gobierno también procuran maximizar la votación de sus subpactos y coalición política, y fortalecer a su coalición con miras a las elecciones presidenciales y futuras contiendas. Cada una de estas realidades puede conducir y —como lo demuestran exhaustivos análisis empíricos- de hecho ha conducido a situaciones en que los dirigentes no siempre escogen, o están en condiciones de inscribir en una lista, al candidato que consideran capaz de reunir la mayor cantidad de sufragios en una determinada circunscripción.

Existen tres niveles en los que se adoptan las decisiones más importantes que determinan la selección del candidato. Primero viene el difícil proceso de toma de decisiones dentro de cada partido. Luego se realizan negociaciones al interior de todos los subpactos para determinar el número de candidatos que cada uno inscribirá en las listas de las coaliciones mayores. En tercer lugar, cada coalición nacional debe emprender negociaciones internas para determinar cuáles candidatos de qué subpactos y partidos competirán en cada circunscripción. Como resultará evidente, estos procesos están estrechamente vinculados y a menudo ocurren simultáneamente. Aquí aparecen separados sólo para fines analíticos.

Selección de candidatos a nivel de partidos individuales. Pese a la escasez de bibliografía académica sobre la selección de candidatos, la que existe sugiere que hay dos extremos en lo que se refiere al centro de control $^{12}$. En un extremo está la selección simple de candidatos realizada únicamente por el dirigente del partido, y en el otro está la selección de los candidatos efectuada por los miembros inscritos del partido o incluso por simpatizantes del mismo. En la mayoría de los casos el poder reside en un punto situado entre estos extremos, lo cual requiere una cierta modalidad de consulta al electorado del partido. Chile no constituye una excepción a esta generalización, si bien los partidos individuales difieren en cuanto al grado de participación de los electores y de militantes del partido.

En el Chile preautoritario la selección de candidatos estaba controlada casi enteramente por las directivas de los partidos, aun cuando su sistema de listas abiertas en distritos de gran magnitud efectivamente proporcionaba al votante un mayor grado de control sobre la selección

12 Gallagher: “Introduction”, 1988, p. 4. 
definitiva de candidatos. Las normas legales posautoritarias aún permiten el funcionamiento de procesos de selección de candidatos centrados en las dirigencias. El artículo 19, No 15 de la Constitución chilena dispone que los “estatutos [de los partidos políticos] deberán contemplar las normas que aseguren una efectiva democracia interna”, pero no hay ninguna referencia a la selección de candidatos propiamente tal. Ahondando en las normas generales delineadas en la Constitución, sin embargo, la Ley Orgánica de Partidos Políticos, o Ley 18.603, establece directrices para la selección de candidatos individuales. La Ley estipula que "los estatutos de los partidos políticos deberán contener normas para que la designación o el apoyo a candidatos a Senadores y Diputados sean efectuados por el Consejo General $^{13}$, a proposición de los Consejos Regionales”. ¿Cómo actúan los partidos dentro del marco de estas directrices legales para escoger candidatos? ¿Con qué grado de descentralización y de cercanía a las bases participan en este proceso los activistas y ciudadanos? ¿Qué variables determinan quién queda definitivamente inscrito en las papeletas de votación?

En la Tabla $N^{\circ} 2$ se resumen los mecanismos de selección de candidatos utilizados por los principales partidos ancla de Chile para cada una de las elecciones celebradas desde el retorno a la democracia, y se demuestra que los partidos difieren en cuanto al grado de participación de los militantes, a nivel de las bases, en la selección de candidatos. Con todo, en la mayoría de los partidos los dirigentes continúan ejerciendo un control de facto, lo cual obedece a varias razones. Los partidos políticos son más similares en estructura a sus equivalentes europeos, donde los candidatos no son escogidos en elecciones primarias como en los Estados Unidos. De modo que no existe una sólida tradición de democracia interna en los partidos chilenos en lo tocante a la selección de candidatos. Incluso en partidos donde se ha introducido alguna forma de comicios primarios las directivas no dejan de ejercer un control de facto, pues son ellas las que suelen proponer al candidato que se presentará a la elección primaria. Finalmente, como se subrayará a lo largo de todo este análisis, las exigencias que impone la formación de coaliciones dificultan la introducción de elecciones primarias, ya que en última instancia son los dirigentes de la coalición los que deben establecer las candidaturas con miras a la victoria de la alianza. Lo anterior significa que a veces es necesario hacer caso omiso de las decisiones de determinados partidos y sus militantes en aras de la unidad de la coalición.

Como lo sugiere la Tabla $\mathrm{N}^{0}$ 2, la participación popular fue casi inexistente en las elecciones de 1989, cuando los partidos no contaban con

${ }^{13}$ Los consejos nacionales están compuestos por senadores, diputados y varios representantes elegidos por cada consejo regional del partido. 
TABLA N ${ }^{\circ}$ 2: $\quad$ MECANISMO PARA LA SELECCIÓN DE CANDIDATOS POR PARTIDO, 1989-2001

\begin{tabular}{l|lllll}
\hline \multicolumn{1}{l}{ Alianza } & Partido & 1989 & 1993 & 1997 & 2001 \\
\hline & PDC & $\begin{array}{l}\text { Juntas } \\
\text { provinciales }\end{array}$ & $\begin{array}{l}\text { Primarias } \\
\text { cerradas }\end{array}$ & $\begin{array}{l}\text { Primarias } \\
\text { cerradas }\end{array}$ & $\begin{array}{l}\text { Primarias } \\
\text { abiertas }\end{array}$ \\
$\begin{array}{l}\text { Concer- } \\
\text { tación }\end{array}$ & PPD & $\begin{array}{l}\text { Junta } \\
\text { Nacional }\end{array}$ & $\begin{array}{l}\text { Junta } \\
\text { Nacional }\end{array}$ & $\begin{array}{l}\text { Junta } \\
\text { Nacional }\end{array}$ & $\begin{array}{l}\text { Junta } \\
\text { Nacional }\end{array}$ \\
& PS & Comité Central & $\begin{array}{l}\text { Comité Central } \\
\text { / Primarias }\end{array}$ & $\begin{array}{l}\text { Comité Central } \\
\text { / Primarias } \\
\text { cerradas }\end{array}$ & $\begin{array}{l}\text { Comité Central } \\
\text { / Primarias } \\
\text { cerradas }\end{array}$ \\
\hline & RN & Consejo & $\begin{array}{l}\text { Consejo } \\
\text { Nacional }\end{array}$ & $\begin{array}{l}\text { Consejo } \\
\text { Nacional }\end{array}$ & $\begin{array}{l}\text { Consejo } \\
\text { Nacional }\end{array}$ \\
& Ulianza & Dirigencia & $\begin{array}{l}\text { Dirigencia } \\
\text { del partido }\end{array}$ & $\begin{array}{l}\text { Dirigencia } \\
\text { del partido }\end{array}$ & $\begin{array}{l}\text { Dirigencia } \\
\text { del partido }\end{array}$ \\
\hline
\end{tabular}

Fuente: Patricio Navia: "Legislative Candidate Selection in Chile”. Trabajo presentado durante la conferencia "Pathways to Power: Political Recruitment and Democracy in Latin America”, Graylyn International Conference Center Wake Forest University, Winston-Salem, NC. 3 a 4 de abril de 2004.

el tiempo, la información y el poder de negociación necesarios para establecer estructuras formales de selección de candidatos. Las directivas de los partidos simplemente decidieron quién competiría en qué circunscripción y contra quién. El proceso de selección de candidatos se ha vuelto más abierto y democrático en el PDC y en el PS (con la introducción de elecciones primarias abiertas y cerradas limitadas, respectivamente), aunque en la mayoría de las colectividades el proceso sigue en manos de las directivas. $\mathrm{Si}$ bien la democratización de la selección de candidatos parecería constituir una plataforma atractiva para un partido, dada la complejidad de la formación de coaliciones, a los partidos les resulta muy difícil ceder el control sobre el proceso de escoger los postulantes.

No obstante, dicho proceso funciona de manera distinta según si la selección es centralizada o si se recurre a las elecciones primarias. Los partidos centralizados, en las fases iniciales de selección de aspirantes, intentan proponer al candidato con el mejor "envase", que resulte atractivo tanto para las bases de la colectividad como para los consejos regionales y nacionales. En los partidos más poderosos las dirigencias (que adoptan diversos nombres: comités centrales, juntas nacionales o consejos nacionales) deben 
examinar extensas listas de candidatos potenciales, con sus posibles circunscripciones correspondientes. Cada candidato es analizado a su vez hasta que se llega a elaborar una lista definitiva de entre 60 y 120 postulantes, teniendo en cuenta las recomendaciones de los consejos regionales. El tamaño de las listas depende de una estimación del partido en cuanto a su fortaleza general, su estrategia de negociación y la cantidad de cupos electorales que aspiran obtener. Para entonces las colectividades suelen estar informadas del número aproximado de circunscripciones en que van a competir y de la ubicación de las mismas (el proceso para determinar esa cifra se analizará a continuación). Los candidatos son asimismo clasificados en función de la voluntad del partido para ceder sus cupos en negociaciones con otros partidos (las que por supuesto son confidenciales). En los partidos menos poderosos se elabora una lista más reducida de candidatos y los dirigentes analizan estrategias de negociación destinadas a lograr la mejor ubicación para sus candidatos en las listas principales.

En los partidos donde se emplea el sistema de elecciones primarias (cerradas en el PS, abiertas en el PDC) el proceso es diferente. Con ello no se pretende sugerir que los procesos de selección de candidatos están en manos de los militantes de los partidos, incluso en aquellos donde se ha observado una democratización limitada. En primer lugar, es difícil superar la tradición de la centralización. En las colectividades donde en elecciones primarias competitivas los militantes no eligen al candidato apoyado por la dirigencia, los activistas locales generalmente tienen la última palabra, aunque en algunos casos los consejos nacionales han invalidado los resultados de los comicios primarios internos. En segundo lugar, en negociaciones posteriores los partidos a menudo deciden ceder un cupo a otra colectividad para así mantener la unidad de la coalición, lo cual significa hacer caso omiso de la decisión de los militantes. Esta situación es bastante habitual y con frecuencia provoca el descontento de candidatos que se sienten como corderos sacrificados en el altar de la unidad de la coalición. Por último, en la mayoría de los casos en que los postulantes son quienes actualmente ocupan el cargo, ellos compiten sin oposición, ante lo cual las primarias resultan innecesarias. Por tanto, incluso cuando se recurre a las elecciones primarias no podemos hablar de una verdadera democracia interna. Es más, Navia señala que para el PDC (el único partido donde se han empleado las primarias abiertas) la introducción de las primarias ha coincidido con un descenso en la tasa de éxito del partido en las elecciones. Mientras que el partido con los procedimientos más centralizados para escoger postulantes (la UDI) ha obtenido un éxito sostenido y cada vez mayor en los comicios, lo cual sugiere que las primarias tal vez no son el mejor método para selec- 
cionar candidatos con posibilidades de ser elegidos ${ }^{14}$. Por tanto resulta improbable una tendencia hacia una creciente democracia interna en los partidos o hacia el uso de las primarias en la designación de candidatos.

¿Cuáles son algunas de las variables que aumentan el atractivo de un candidato? Meses antes de las elecciones los militantes de los partidos comienzan a asumir posturas electoreras para presentarse como potenciales candidatos al parlamento. La fortaleza que proyectan los candidatos determina su éxito a lo largo de cada uno de los niveles del proceso de selección. Por ejemplo, la capacidad de un aspirante en particular para competir con mayor éxito frente a un contendor poderoso de la oposición inscrito en una determinada circunscripción puede ser un factor decisivo que conduzca a la designación del primero como candidato del partido. Un candidato más poderoso puede exigir una mejor circunscripción y otorgar a su partido una mayor capacidad de negociación al interior de la coalición en su conjunto. Así pues, cuando el proceso de negociación se pone en marcha, los partidos procuran encontrar los candidatos más poderosos para situarlos en las “mejores” circunscripciones.

Ahora bien, ¿qué determina la fortaleza de un candidato? Como ocurre en la mayoría de los sistemas de partidos que cuentan con una adecuada institucionalidad, existe cierto grado de regularidad en la representación de los partidos en el Congreso ${ }^{15}$. Por ende, como cabría esperar, la titularidad en el cargo es una excelente variable predictiva para determinar si un candidato será renominado. Entre 1993 y 2001 las tasas de renominación para diputados alcanzaron un promedio de 73,3\% (renominados para la circunscripción donde ejercían sus funciones, o para otra circunscripción, o para el Senado). El 82,3\% de los renominados fue reelecto ${ }^{16}$. Entrevistas con dirigentes de todo el espectro de tendencias políticas confirmaron que se da por sentado que los titulares en el cargo tienen el derecho a ser renominados, salvo en el caso de extrema indisciplina del candidato.

Además, los candidatos conocidos a nivel nacional resultan atractivos para los consejos nacionales y regionales de los partidos. Un ex ministro o un destacado dirigente de una colectividad política es más influyente en el parlamento, lo cual es bien visto por los consejos regionales de los partidos que están interesados en la capacidad de los diputados para otorgar favores políticos. Ello ocurrió claramente en la $5^{\mathrm{a}}$ circunscripción senatorial (Cordillera), donde Carlos Ominami, ex ministro de Economía, consiguió fácilmente la nominación del Partido Socialista (derrotando a Isa-

\footnotetext{
${ }^{14}$ Navia, Patricio: "Legislative Candidate Selection in Chile", 2004.

${ }^{15}$ Mainwaring, Scott y Timothy Scully: "Introduction”, 1985, p. 6.

${ }^{16}$ Navia: "Legislative Candidate Selection in Chile”, 2004.
} 
bel Allende, hija del ex primer mandatario) en una elección interna competitiva, y continuó en campaña hasta ganar un escaño en el Senado en 1993.

Por último, como sugiere la referencia anterior (pese a la derrota de Isabel Allende), el apellido ha demostrado ser extremadamente importante en Chile en lo que se refiere al atractivo de los candidatos. El hecho de tener el apellido adecuado puede ayudar considerablemente en la lucha por una candidatura parlamentaria. Durante el período 1993-1997 el Senado contó con un Alessandri, dos Frei, un Letelier y dos Zaldívar, todos apellidos tradicionalmente importantes en la política chilena. Del mismo modo, un Allende, dos Alessandri, y dos Letelier formaron parte de la Cámara de Diputados durante el período 1997-2001.

Una vez que cada partido define la lista preliminar de candidatos, ella debe ser compatibilizada con el acuerdo general al que han llegado los subpactos y las coaliciones nacionales. Este proceso suele completarse cuando concluyen los procesos internos de toma de decisiones de los partidos.

Negociaciones entre subpactos. La totalidad del proceso de selección de candidatos se complica mucho más tan pronto como deja de ser un asunto que incumbe a un solo partido. Éste es específicamente el caso de aquellas colectividades políticas que ocupan una posición minoritaria dentro de coaliciones y subpactos más amplios.

Pese a tener diferencias programáticas, los partidos chilenos con un nexo ideológico se han aliado para formar "subpactos" (para un desglose de los mismos es preciso volver a analizar la Figura $\mathrm{N}^{\circ} 1$ ). Por ejemplo, los partidos de izquierda que integran la Concertación han formado un subpacto compuesto por el PS y el PPD. Ambos partidos tienen raíces comunes dentro del tradicional Partido Socialista chileno. Con todo, las continuas divisiones de tipo programático, ideológico y personal impidieron que se fusionaran durante el proceso de transición. Así y todo, han formado un subpacto en un esfuerzo por proporcionar una voz unificada de los partidos que están en la izquierda del espectro político. Conflictos similares en la derecha han conducido a la creación de dos subpactos dentro de la alianza de centro-derecha Unión por el Progreso, sustentados cada uno por los dos principales partidos (RN y la UDI), a los cuales se integran una serie de candidatos "independientes" y de partidos pequeños.

Existen numerosas evidencias de que el sistema binominal no ha conseguido reducir la cantidad de partidos pequeños, pero histórica y políticamente significativos ${ }^{17}$. De todas maneras, en lugar de limitarse a fusio-

${ }^{17}$ Siavelis y Arturo Valenzuela: "Electoral Engineering and Democratic Stability: The Legacy of Authoritarian Rule in Chile”, 1996; Valenzuela y Scully: "Electoral Choices and the Party System in Chile: Continuities and Changes at the Recovery of Democracy”, 1997. 
narse con otros partidos más grandes, estas colectividades políticas también se han incorporado en uno de los subpactos con los que tienen algún grado de afinidad ideológica. El Partido Radical, el Partido Social Demócrata, el Partido Verde y otros se han integrado en uno de los dos subpactos de la Concertación para así mantener su influencia en la coalición. Debido a las características excluyentes del sistema electoral, los partidos pequeños saben que la única manera de conseguir escaños legislativos es negociar para unirse a una coalición más grande.

¿Qué incentivos tienen los partidos más grandes para permitir el ingreso de colectividades más pequeñas? Dada la importancia de los umbrales electorales del sistema, los partidos más grandes están dispuestos a compartir la asignación de una pequeña cantidad de cupos electorales en algunas circunscripciones a cambio de votos anticipados extra que pueden ayudar a las alianzas electorales a cruzar uno de los umbrales decisivos en otras circunscripciones. Un aspecto adicional no menos importante se refiere a que la admisión de un partido minoritario en el rebaño de la coalición sirve para evitar la presentación de otras candidaturas presidenciales de pequeños partidos que puedan erosionar el apoyo a candidatos presidenciales de coaliciones más grandes. La importancia de las candidaturas presidenciales unificadas quedó reafirmada por la estrecha mayoría relativa que obtuvo el socialista Ricardo Lagos en la primera vuelta de la elección presidencial de 1999, donde la distancia que separó a los dos candidatos con mayor votación fue de $0,5 \%$. Si bien se podría argumentar que la disposición de la Constitución chilena que establece la celebración de una segunda vuelta disminuye los riesgos de formar una coalición para competir por la presidencia, los partidos de hecho prefieren evitar en lo posible esa segunda vuelta.

Tan importante como lo anterior resulta el que las coaliciones procuren incluir a partidos menores para así evitar que se unan a otra alianza o a otro subpacto. Que un partido pequeño se vaya a una coalición —o subpacto - rival puede ser potencialmente muy peligroso en cuanto a los niveles nacionales de apoyo. Los partidos pequeños lo saben e intentan usar esta circunstancia como mecanismo de influencia para obtener la mayor cantidad posible de escaños de los partidos ancla del subpacto. Durante el período previo a las elecciones de 1993 la UCC flirteó con los partidos de todo el espectro político a fin de conseguir el máximo número posible de candidaturas de potenciales socios de coalición ${ }^{18}$. La derecha sacrificó una importante cantidad de candidatos por temor a que la UCC llegara a aliarse

18 “Consejo General de RN Rechaza Pacto con UCC”, El Mercurio 23 de mayo de 1993. 
con la Concertación. Una dinámica similar ocurre incluso entre partidos de la misma coalición. En la etapa preparatoria de las elecciones de 1997, el pequeño PRSD se declaró efectivamente en libertad de acción, informando a los subpactos democratacristiano y PS-PPD que se incorporaría a aquel que le ofreciera la mejor fórmula de acuerdo en términos de candidaturas. De hecho, para las elecciones de 2001 el PRSD abandonó el subpacto del PDC para unirse al PS-PPD. Es así como los partidos más pequeños pueden usar su influencia (a menudo con mucha eficacia, especialmente en el caso del PRSD $)^{19}$, para crear batallas de ofertas entre los partidos más poderosos que lideran los subpactos. Se trata, no obstante, de un juego peligroso, puesto que esas ofertas cesarán cuando los costos de acceder a las exigencias de escaños formuladas por un determinado partido excedan los beneficios electorales que ello pueda reportar.

Luego de constituidos los subpactos, cada uno debe decidir cuántos candidatos se asignarán a cada partido antes de entablar negociaciones para elaborar la lista de la coalición a nivel nacional. La dinámica de comportamiento de cada partido en las negociaciones entre subpactos varía de acuerdo con su tamaño. Por ejemplo, como el subpacto de la izquierda al interior de la Concertación incluye dos partidos poderosos (el PS y el PPD), con aproximadamente el mismo nivel de apoyo nacional, cada uno comienza por suponer que recibirá la mitad de la cuota de escaños asignada al subpacto. Luego los partidos emplean los sondeos de opinión pública y los resultados de las elecciones municipales para intentar aumentar su grado de influencia y conseguir más cupos electorales, antes de iniciar negociaciones con el subpacto de centro para elaborar las listas electorales de la Concertación.

Formulación de listas de las coaliciones. Mientras cada uno de los partidos escoge candidatos, y los subpactos elaboran trabajosamente propuestas de listas preliminares, tiene lugar un tercer proceso simultáneo. Representantes de cada subpacto determinan la cantidad de cupos de partido que recibirán en las listas nacionales de la coalición. Este proceso se caracteriza por negociaciones entre las directivas que se efectúan tanto

${ }^{19}$ El PRSD (que en ese entonces — antes de fusionarse con el Partido Social Demócrata tras las elecciones de 1993- se llamaba sólo Partido Radical) se aseguró un número de candidatos superior al que le habría correspondido según su nivel nacional de apoyo. En 1993 recibió 11 de los 120 cupos de la Concertación (casi el 10\%), mientras que sólo logró obtener cerca del 3\% de la votación a nivel nacional; en 1997 consiguió 8 cupos, y al cambiarse al subpacto PS-PPD logró 14. Sin embargo, la realidad adicional de que el PRSD también procuraba alcanzar el umbral mínimo de $5 \%$ para mantenerse como partido político lo llevó a aceptar muchos escaños en circunscripciones donde no tenía posibilidades razonables de triunfo. 
fuera como dentro de las estructuras formales de los partidos y de las alian$\mathrm{zas}^{20}$. Aun cuando muchos aspectos de la Concertación se encuentran sumamente estructurados, ello no ocurre con el proceso de selección de candidatos entre los principales partidos; una situación similar se observa en la centro-derecha. En todo el espectro de partidos son los miembros de alto nivel y sus expertos electorales quienes participan en las negociaciones, aunque los acuerdos finales deben contar con la aprobación del consejo nacional de cada partido.

En esta fase del proceso de selección de candidatos las peguntas más complejas y acuciantes que se plantean a las coaliciones son las siguientes: ¿De qué manera se distribuirán los escaños entre los principales subpactos de cada coalición? ¿Cuántos escaños se cederán a los socios más pequeños en los subpactos? ¿Cómo se distribuirán las candidaturas en cada circunscripción? ¿Con quiénes formarán duplas los candidatos?

Normas para negociar candidatos dentro de las coaliciones. Las respuestas a las interrogantes anteriores están condicionada fundamentalmente por los umbrales electorales ya analizados. Todos los partidos y subpactos se dan cuenta de que resulta muy difícil que las coaliciones consigan obtener los dos escaños de una determinada circunscripción. Para lograr ese objetivo se requiere comúnmente reunir una votación total de $66 \%$ para la lista. Así pues, es probable que por lo menos uno de los dos candidatos en la lista de una coalición resulte derrotado. Por consiguiente, la clave para la victoria es que el candidato del subpacto o partido vaya acompañado en la lista con un candidato extremadamente poderoso (que ayudará a obtener el improbable triunfo de dos escaños con el 66\%), o bien vaya en la misma lista con un candidato débil (que le ayudará a cruzar el umbral del 33\%, pero que no lo superará en votos). Esta realidad básica determina el proceso de formación de alianzas y la manera en que los candidatos son inscritos en cada circunscripción. Entrevistas con dirigentes encargados de escoger a los candidatos en cada uno de los principales partidos políticos en 1999 y 2000, al igual que ejemplos empíricos, sugieren la existencia de una lógica constante en los tipos de candidatos con los que otros postulantes tratan de formar duplas, y en los tipos de duplas que prefieren los subpactos.

Pese a lo anterior, la evidencia empírica que se menciona a continuación también sugiere la existencia de otra variable esencial que afecta a las reglas de negociación al interior de las coaliciones: la fuerza relativa de los

20 "Las Corrientes Ocultas tras las Negociaciones", La Segunda, 19 de febrero de 1993, p. 13. 
principales subpactos y partidos que las componen. Por ejemplo, los partidos ancla en los subpactos actúan de manera distinta según si el subpacto que encabezan goza o no de un nivel de apoyo similar al de otros subpactos poderosos. Una vez más, teniendo en cuenta los umbrales del sistema electoral, dos subpactos estarán dispuestos a repartirse equitativamente los escaños en una situación en que cuentan con un nivel de apoyo relativamente similar en todo el país. Sin embargo, si un subpacto constantemente va a la zaga de otro a nivel nacional, se mostrará reacio a aceptar la simple alternativa de repartirse las circunscripciones con un subpacto poderoso, ya que ésta es una fórmula segura para ser derrotado en todas las circunscripciones a nivel nacional. El estratégico ordenamiento por preferencia de los partidos se ve, por tanto, afectado además por la fuerza relativa de su respectivo subpacto. Más aun, los partidos pequeños encaran un dilema diferente dentro del sistema binominal, y por ende también tienen que adoptar una estrategia distinta para maximizar su influencia y ganar escaños. Las Figuras $\mathrm{N}^{\circ} 2$ y $\mathrm{N}^{\circ} 3$ sistematizan estas reglas y clasifican las selecciones óptimas de los partidos pequeños y de los grandes. Las figuras muestran, asimismo, variaciones en el orden de las preferencias de los partidos según sea la fuerza relativa de su subpacto. La Figura $N^{\circ} 2$ representa estas opciones en las negociaciones "intracoalición" en que los dos principales subpactos se encuentran en una situación de relativa paridad en cuanto a apoyo; mientras que la Figura $\mathrm{N}^{\circ} 3$ muestra los incentivos del sistema donde existe disparidad en el nivel de apoyo para los dos subpactos de una coalición. Los números dentro de los círculos representan la clasificación de las preferencias para los partidos.

Para los fines del análisis posterior, el término "posición" se refiere a los niveles nacionales de apoyo basados en sondeos de opinión pública y en la votación obtenida en las elecciones anteriores. La expresión "partido ancla" alude a los partidos más poderosos en torno a los cuales se aglutina un subpacto (el PDC, el PPD y el PS ${ }^{21}$ en la Concertación, y RN y la UDI en la Unión por Chile), y un partido menor es cualquier otro socio más pequeño del subpacto.

Las Figuras $\mathrm{N}^{\circ} 2$ y $\mathrm{N}^{\circ} 3$ muestran que cuando los subpactos se encuentran con diferentes niveles de apoyo, el orden de preferencias de los partidos al interior de los subpactos cambia, y la naturaleza de las negociaciones dentro de las coaliciones probablemente será distinta. Fundamentalmente, allí donde los subpactos cuentan con niveles similares de apoyo

${ }^{21}$ El PS y el PPD con considerados como un solo partido ancla para los fines de este análisis (como también ocurriría con otros partidos que buscaran llegar a un acuerdo en torno a la cantidad total de candidaturas para cada partido antes de que tengan lugar las negociaciones a nivel de coaliciones. 
FIGURA N ${ }^{\circ}$ 2: REGLAS PARA NEGOCIACIONES INTRACOALICIÓN EN UNA SITUACIÓN DE PARIDAD ENTRE SUBPACTOS

(Los subpactos clasificados en primer y segundo lugar obtienen aproximadamente el mismo respaldo)

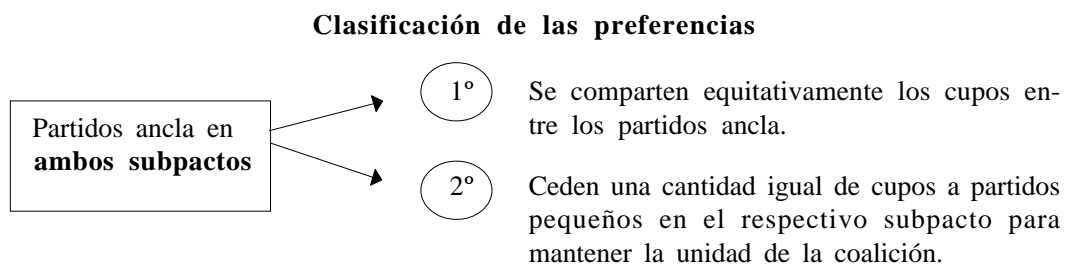

Clasificación de las preferencias

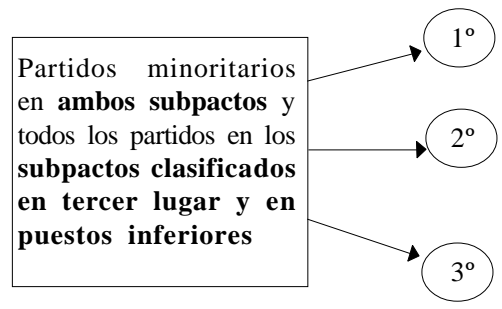

Buscan candidatos de partidos minoritarios como compañeros de lista.

Buscan candidatos muy débiles de un partido ancla de cualquiera de los dos subpactos como compañeros de lista.

Buscan compañeros de lista muy poderosos de un partido ancla, con el potencial de ganar dos escaños (doblar).

dentro de una coalición, sus estrategias para maximizar la cantidad de escaños son idénticas. Ellos procuran repartirse las candidaturas y sólo ceder una pequeña cantidad de cupos a partidos pequeños para mantener la unidad de la coalición. Con todo, cuando los subpactos clasificados en segundo lugar se encuentran próximos al primer subpacto a nivel nacional, deben tratar de evitar formar duplas con candidatos del subpacto más poderoso y buscar, en cambio, un socio más débil, o bien deben intentar aliarse con un socio muy poderoso del subpacto clasificado en primer lugar, el cual les permitirá superar el segundo umbral y ganar así los dos escaños de la circunscripción.

Reglas para negociar los candidatos al interior de las coaliciones. Un análisis del proceso de selección de candidatos en las primeras tres elecciones del período posautoritario arroja luz sobre la manera en que estas reglas funcionan en la práctica. En la primera elección democrática posautoritaria de 1989 el proceso de selección de candidatos se vio complicado por una negociación esencialmente a ciegas, dada la falta de sondeos de opinión pública o resultados electorales recientes sobre los cuales los partidos 
FIGURA N ${ }^{\circ} 3$ :

REGLAS PARA NEGOCIACIONES INTRACOALICIÓN EN UNA SITUACIÓN DE DISPARIDAD ENTRE SUBPACTOS

(Partidos clasificados en primer y segundo lugar con niveles de apoyo diferenciales)

\section{Clasificación de las preferencias}

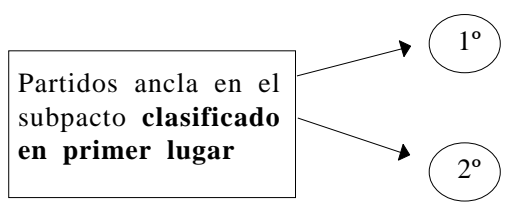

Busca un mínimo de un cupo en cada circunscripción; obliga a los socios de la coalición a ceder cupos.

Cede una cantidad limitada de cupos a partidos pequeños del subpacto para mantener la unidad de la coalición; el socio de coalición también cede cupos.

\section{Clasificación de las preferencias}

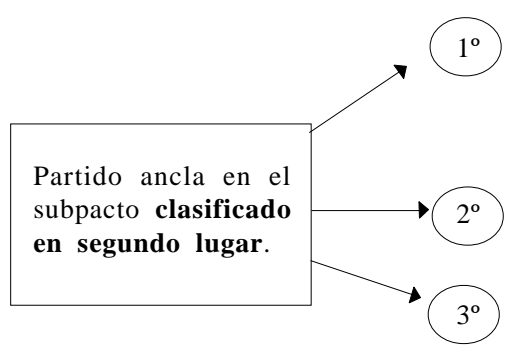

Procura negociar algunas circunscripciones con dos cupos para evitar la competencia con el partido ancla del subpacto clasificado en primer lugar.

Busca compañeros de lista muy débiles del subpacto clasificado en primer lugar.

Busca compañeros de lista muy poderosos del subpacto clasificado en primer lugar para así conseguir dos escaños (doblar).

\section{Clasificación de las preferencias}

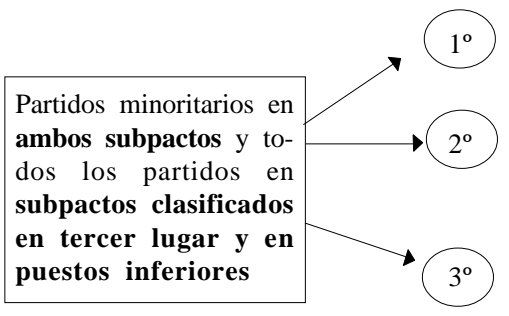

Buscan candidatos de partidos minoritarios como compañeros de lista

Buscan compañeros de lista muy débiles de un partido ancla de cualquiera de los dos subpactos.

Buscan compañeros de lista muy poderosos de un partico ancla del subpacto clasificado en primer o segundo lugar con el potencial de ganar dos escaños (doblar).

pudieran basar sus proyecciones de apoyo. Por cierto que cada uno de ellos afirmaba ser el líder de su correspondiente sector ideológico. Al mismo tiempo, los intereses en juego eran de extrema importancia, pues la distribución de los candidatos determinaría en parte el grado de apoyo nacional que un partido recibiría en las elecciones, y de este modo influiría en el poder relativo de los partidos y en la selección de candidatos para las elecciones futuras. Los partidos rápidamente se percataron de la absurda 
dinámica competitiva del sistema, y comprendieron que ganar los dos escaños en una circunscripción era improbable. En el caso de la Concertación, el hecho de presentar listas separadas en el centro y la izquierda habría proporcionado un triunfo a la derecha y habría disminuido la probabilidad de que un candidato de la Concertación llegara a la presidencia. La urgencia de la situación y el objetivo general de derrotar a los candidatos ligados al gobierno anterior generó un espíritu de concesiones mutuas que no estaría presente en las siguientes tres elecciones parlamentarias.

Con lo anterior no se pretende sugerir que el proceso de formación de listas en la Concertación estuviera exento de conflictos. Cuando se inició el proceso de negociaciones los partidos de la izquierda (PS-PPD) se encontraban en una posición ventajosa para conseguir concesiones de los democratacristianos y su subpacto "Coalición Chica" (PDC-PAC-PR-PSDP). Sin embargo, el surgimiento de una lista paralela en la izquierda, el PAIS (Partido Amplio de Izquierda Socialista), compuesta de partidos que rehusaron participar en la Concertación (incluidos los comunistas y los socialistas disidentes), complicó el panorama de las negociaciones. Por una parte, la fragmentación de la izquierda proporcionó al PDC pábulo para afirmar que ese sector en realidad se había dividido y, por tanto, tenía derecho a menos escaños en la lista de la Concertación. Por otra parte, el PDC tuvo que comprometerse a proporcionar a la izquierda suficientes escaños para así erradicar la posibilidad de una completa desintegración de la Concertación cuando la izquierda moderada abandonara el barco de la coalición para unirse a la lista del PAIS. En el peor de los casos posibles ello se habría traducido en una candidatura presidencial por separado de la izquierda. Paralelamente, los partidos de la izquierda, contando con la posibilidad de heredar apoyo del históricamente poderoso Partido Comunista, tuvieron que superar las potenciales dificultades de malquistarse con un importante sector del electorado aliándose con la Concertación y rechazando la formación de una lista separada de la izquierda ${ }^{22}$.

En definitiva, los partidos de la Concertación acordaron que las circunscripciones serían repartidas equitativamente entre los subpactos de la izquierda y del centro, con algunos ajustes menores basados en la disposición de cada subpacto a acoger a partidos más pequeños. Hubo también un acuerdo tácito entre el subpacto PS-PPD, el subpacto del PDC y el PAIS. La Concertación distribuiría los candidatos igualitariamente entre sus dos subpactos, excepto allí donde el PAIS estuviera presentando una lista. En

22 Para un análisis de esta dinámica véase El Mercurio 11 de junio de 1989, p. D4; La Época, 22 de junio de 1989. 
esas circunscripciones se inscribirían dos candidatos del centro para así evitar que se dividiera el apoyo a la izquierda. Es más, la lista del PAIS accedió a respaldar a los candidatos de la Concertación allí donde éste no presentara su propia lista. El PDC, en su calidad de partido ancla del subpacto, aprovechó la ventaja de obtener dos escaños en algunas circunscripciones al distribuirlos entre sus socios de partidos minoritarios, logrando así satisfacerlos y mantener al mismo tiempo su predominio. Aun así, el PDC sabía que al contar con un mayor nivel de apoyo nacional probablemente tenía garantizada la victoria en las circunscripciones donde sus candidatos formaban duplas con otros de partidos pequeños del subpacto.

Con el paso del tiempo y transcurridas varias elecciones, el proceso de selección de candidatos se ha tornado menos armonioso y más complejo. El consenso forzoso generado por el proceso de transición al interior de ambas coaliciones prácticamente se ha desvanecido.

A la luz de estos cambios, el proceso de negociación para la elección de 1993 fue distinto. Los dirigentes de la Concertación contaban con datos de dos elecciones anteriores sobre los cuales basar las negociaciones. Los resultados de las elecciones parlamentarias de 1989, y municipales de 1992, se convirtieron en importantes fuentes de contrapeso para negociar las candidaturas. Los resultados de las elecciones municipales han servido históricamente como indicadores de aprobación para el gobierno y de la fortaleza de los partidos ${ }^{23}$. El exitoso desempeño del PDC en estos comicios le otorgó al partido un poder de negociación adicional.

Finalmente, en 1993 la Concertación llegó a un acuerdo similar al de las elecciones de 1989. Los subpactos PS-PPD y democratacristiano accedieron una vez más a dividir la lista, pero al igual que en 1989 se decidió introducirles algunos pequeños ajustes. El PDC adujo su excelente desempeño en el gobierno y en las elecciones como fundamento para obtener un número mayor de candidaturas parlamentarias. El subpacto PS-PPD aceptó ceder cinco circunscripciones al subpacto democratacristiano si el PDC se comprometía a usar esos cinco escaños, y otros cinco adicionales de su propiedad, para inscribir a candidatos de partidos menores. De esta manera la democracia cristiana presentaría 55 candidatos, sus socios menores de la lista del subpacto (el PR, la SD y el PAC) presentarían 10, y el PS-PPD 55, para llegar a un total de $120^{24}$. Tras determinar la cantidad total de escaños que serían asignados a los subpactos, cada uno de éstos realizó una serie

${ }^{23}$ El Mercurio 17 de febrero de 1993, p. C5.

${ }^{24}$ Para un completo desglose de todos los partidos que constituyeron la Concertación (hubo otros muy minoritarios fuera de los 11 enumerados en la Tabla 2), véase El Mercurio, 21 de mayo de 1989, p. C5. 
de ajustes que en último término permitieron transferir algunos escaños más a los partidos menos poderosos 25 .

El proceso de negociación en la centro-derecha no fue tan fluido. La UCC (Unión de Centro Centro) - en ese entonces un partido relativamente nuevo- había recibido alrededor del 7\% de los votos en las elecciones municipales, y fue percibida como un potencial aguafiestas que podría arrebatarle votos a la coalición centro-derechista, haciéndola descender a un nivel inferior al umbral electoral de 33\%. Había además una incipiente candidatura presidencial de la UCC, la que debilitaría la votación de la derecha en las elecciones presidenciales. La principal interrogante que se planteaba en 1993 era si incluir o no a la UCC en la coalición de centro-derecha, y en caso afirmativo, cómo distribuir los cupos entre los tres partidos de la derecha. A la UCC se le asignó un número de candidatos muy superior a la votación que su nivel nacional de apoyo permitía vaticinar, principalmente para evitar dividir la votación de la derecha en las elecciones presidenciales, lo cual habría ocurrido si la UCC presentaba su propio candidato. La alianza Unión por el Progreso obtuvo este beneficio a un costo muy bajo. Pese a su elevado número de candidatos, la UCC sólo consiguió elegir dos diputados propios, uno de los cuales renunció a la colectividad para prontamente incorporarse en Renovación Nacional ${ }^{26}$.

La última variable importante considerada en la elaboración de listas es la combinación de candidatos en cada lista. Como ya se señaló, dados los umbrales establecidos por el sistema electoral, resulta difícil presentar una lista de candidatos capaz de reunir el 66\% de la votación necesario para conseguir una victoria de dos escaños (o "doblar") en una determinada circunscripción. Por consiguiente, queda claro que en la mayoría de las circunscripciones un candidato va a ganar y uno va a perder, tanto en la centro-derecha como en la centro-izquierda. (En las últimas cuatro elecciones — 1989, 1993, 1997 y 2001— la Concertación consiguió doblar en la 11ª $9^{\mathrm{a}}$ y $4^{\mathrm{a}}$ circunscripciones y los partidos de la centro-derecha doblaron en sólo dos oportunidades, una en 1993 y una en 2001).

Esta realidad ha dado lugar a sugerencias en la prensa y en debates populares sobre el sistema electoral en cuanto a que sería muy recomendable que las coaliciones aplicaran una estrategia de "débil-fuerte”. Es decir,

${ }^{25}$ De los 65 candidatos del pacto del PDC, el PDC presentó 48, el PR 11, la SD 4, además de 2 independientes asociados. En el subpacto PS-PPD las candidaturas se desglosaron de la siguiente manera: 28 para el PS, 25 para el PPD y 2 candidaturas independientes. Datos Ministerio del Interior, sitio en internet "Elecciones históricas", www.elecciones.gov.cl/1993.

${ }^{26}$ Auth, José: “Elecciones Presidenciales y Parlamentarias de 1993”, 1994, pp. 339-362. 
presentar un candidato capaz de reunir suficientes votos para traspasar el primer umbral electoral, y ponerle como compañero de lista a uno más débil cuyos votos simplemente aseguren que el primer candidato cruce el umbral, pero cuyas posibilidades de conseguir un escaño son escasas. Aun cuando sea lógica y a veces se la emplee con claridad, existen pocas evidencias de que esta estrategia se aplique de manera tan generalizada como algunos sugieren. Fundamentalmente, la conveniencia de una estrategia de fuertedébil depende de múltiples variables.

Si cada partido estuviera elaborando listas individuales, podría haber más de un incentivo para emparejar a los candidatos débiles con postulantes fuertes, especialmente en circunscripciones donde los partidos no pueden esperar reunir un porcentaje de la votación cercano al 66\%. Sin embargo, en un sistema que crea una alta demanda de cupos y la oferta es escasa, y donde existen numerosos partidos y por tanto hay una abundante oferta de aspirantes a candidaturas, los partidos se resistirán a permitir que sus candidatos sean los miembros débiles en las listas que combinan fuertes con débiles. Existen, por cierto, excepciones. Por ejemplo, el PRSD ha estado dispuesto a aceptar el lado débil en las duplas de candidatos, pues también tiene que preocuparse de mantener el 5\% de la votación necesario para seguir siendo un partido legalmente constituido. Asimismo, hay una pizca de verdad en esta lógica sugerida, en cuanto a que las alianzas pueden abstenerse de presentar dos candidatos extremadamente populares en la misma circunscripción para así evitar que se desperdicien los votos ${ }^{27}$. Así y todo, más que de un simple cálculo sobre cuál candidato es débil y cuál es fuerte, la dupla de candidatos dependerá de la importancia de la circunscripción para el partido (dos candidatos muy fuertes pueden formar duplas en Santiago, Valparaíso o Concepción, por ejemplo), de la votación proyectada para la circunscripción, de cualquier vínculo regional que los candidatos puedan tener con el electorado y, como se ha sugerido anteriormente, de la propia lógica de la negociación dentro de las coaliciones. Es así como en muchos casos se presentan dos postulantes fuertes, incluso cuando los partidos saben que uno de ellos va a perder.

Los dirigentes de los partidos también procuran formar duplas con los candidatos que no se enzarzarán en un conflicto mutuamente destructivo. En situaciones en que la votación esperada por ambos miembros de una coalición es relativamente estrecha, existe un incentivo para entablar una competencia dentro de las listas. Los expertos reconocen que lo anterior sucede rara vez y que los candidatos “prefieren” la cooperación a la con-

${ }^{27}$ Véase, El Mercurio, “Piñera al Borde del Sí”, 30 de marzo de 1997. 
frontación cuando están en campaña ${ }^{28}$. Con todo, sí se dan casos de competencia caníbal, como ocurrió de manera bastante clara en las elecciones de 1989 en una importante circunscripción de Santiago, donde el candidato de RN Sebastián Piñera solía discrepar en público con el representante de la UDI, Hermógenes Pérez de Arce, su presunto “compañero" de lista.

El surgimiento de la competencia dentro de las listas no es meramente un asunto de preferencia, sino que más bien depende de algunas variables que ayudan a determinar si ella ocurrirá o no. Si los candidatos entran a competir en la elección con un porcentaje relativamente similar en los sondeos de opinión pública, es más probable que tenga lugar una pugna dentro de la lista. Ello sucede especialmente cuando da la impresión de que sólo uno de los candidatos de la lista será elegido. Incluso cuando parece que se dispone de suficientes votos para elegir a dos candidatos en una determinada circunscripción, el hecho de recibir la primera mayoría aumenta el atractivo y el poder de negociación de un candidato con miras a futuras elecciones. No obstante, los candidatos suelen entrar en un juego distinto, de velado canibalismo electoral, al sugerir que su compañero de lista cuenta con votos suficientes, y que los electores deberían tratar de otorgar a toda la lista de candidatos de la coalición una "victoria equilibrada".

La combinación de candidatos en cada lista es también importante en otros aspectos. En las elecciones de 1993 la coalición Unión por el Progreso obtuvo mejor votación en las circunscripciones donde presentó un candidato de cada uno de los partidos ancla de sus dos principales subpactos (RN-UDI), en lugar de presentar dos candidatos del mismo partido o un representante de un partido junto con un independiente. En las 16 circunscripciones donde compitieron candidatos de los dos partidos ancla se obtuvo el $43,4 \%$ de la votación total (un 6,8\% más de lo que se consiguió a nivel nacional, y un 7,9\% más de lo que los candidatos presidenciales de la derecha recibieron en estas circunscripciones). Del mismo modo, en el caso de la centro-izquierda, en las circunscripciones donde miembros de la Social Democracia (SD) y del Partido Radical formaron duplas con candidatos del subpacto PS-PPD, los partidos más pequeños no lograron ganar escaños. En las 11 circunscripciones donde se aplicó esta combinación, la separación entre los votos reunidos por los candidatos SD-PR y los conseguidos por los postulantes PS-PPD fue de $18,7 \%$ en promedio ${ }^{29}$. Por tanto, tal parece que las listas compuestas por partidos ancla poderosos obtienen mejores resultados que aquellas que tienen como miembro a un partido más peque-

${ }^{28}$ Rabkin: "Redemocratization, Electoral Engineering, and Party Strategies in Chile, 1989-1995”, 1996, p. 346.

${ }^{29}$ Auth: “Elecciones Presidenciales y Parlamentarias de 1993”, 1994, pp. 353-355. 
ño y menos poderoso ${ }^{30}$. Sin embargo, los partidos menores obtienen de todas maneras una buena votación en las listas de las coaliciones a nivel nacional, si bien las listas compuestas sólo por candidatos de partidos ancla poderosos permitirían maximizar aun más la votación total de las listas en una determinada circunscripción. En esencia, los partidos grandes pagan el precio de recibir un total de votos más bajo a nivel nacional para así mantener la coalición y presentar candidaturas presidenciales unificadas.

Tamaño de los subpactos y dinámica de selección y competencia. Un aspecto que tal vez resulte más importante que las variables analizadas anteriormente se refiere a que el sistema binominal también genera una particular lógica de negociación que depende del tamaño relativo del subpacto (entendiéndose por tamaño los niveles de apoyo nacional). Esta lógica afecta tanto a las negociaciones como a la naturaleza de las concesiones mutuas entre distintos objetivos. Si los dos subpactos dentro de la misma coalición tienen un tamaño aproximadamente similar, las negociaciones de escaños resultan mucho menos conflictivas. Si ambos pueden dar por sentado que obtendrán cerca del 50\% de la votación, las coaliciones tratarán de presentar un candidato de un partido grande de cada subpacto en todas las circunscripciones, y simplemente dejar que los votantes decidan. Sin embargo, si un subpacto poderoso se encuentra en el $60 \%$ o cerca de ese nivel, y el otro sólo puede contar con recibir alrededor del $40 \%$ de los votos de la coalición, este último podría esperar ser derrotado en todas las circunscripciones. En estas situaciones, el principal objetivo de los subpactos clasificados en segundo lugar consiste en conseguir que candidatos de partidos populares del subpacto más grande se bajen de su respectiva lista. Es decir, formar duplas en listas de la coalición junto con un partido más débil. Así pues, los partidos pequeños no sólo negocian para lograr candidaturas en las listas principales, sino que además procuran competir en las listas junto con otros partidos más pequeños y no con los grandes.

Esta lógica queda clara en la evolución de la competencia entre partidos en la derecha a lo largo de sucesivas elecciones ${ }^{31}$. En 1989, los dos principales subpactos de la derecha, encabezados por RN y la UDI, acordaron en un comienzo limitarse principalmente a dividir las listas y presentar un candidato de cada subpacto. Sin embargo, al ser la UDI un partido relativamente nuevo y carente de estructuras establecidas para reclutamiento

${ }^{30}$ Una explicación alternativa es que los partidos más grandes con mayor poder negociador reservaron estas circunscripciones para sí.

31 Tengo una deuda de gratitud con Andrés Allamand por haberme participado sus percepciones sobre la evolución de la competencia en la derecha. 
político, de hecho le resultó difícil identificar candidatos para llenar un cupo en cada lista electoral, y sólo logró inscribir 30 candidaturas (aunque varios de los 23 candidatos independientes presentados en la lista de la Alianza estaban en realidad asociados a la UDI). En contraste, dado su carácter más establecido, RN consiguió inscribir 66 candidatos, en rigor más de la mitad de la cuota que le correspondía. Tras la elección de 1989 quedó de manifiesto que RN había adquirido preponderancia en la derecha, pues en las elecciones para la Cámara de Diputados reunió el 18,3\% de la votación, frente al 9,8\% de la UDI ${ }^{32}$. Ello le otorgó a RN una posición dominante al entablar las negociaciones para la próxima elección.

No obstante, durante el período que antecedió a la elección de 1993 la situación se complicó al entrar en escena un nuevo participante en la derecha. Como ya se indicó, la votación obtenida por la UCC (Unión de Centro Centro) $^{33}$ en las elecciones municipales de 1992 la estableció como actor potencial en la derecha. Los dos partidos principales de ese sector reconocieron la necesidad de aumentar los totales generales de las listas de la coalición para lograr traspasar los umbrales críticos a nivel nacional. Fue así como la UCC comenzó a promocionarse como una alternativa poderosa capaz de contribuir significativamente al total nacional de votación de las listas parlamentarias de la derecha.

Debido al predominio de RN en la derecha, los dirigentes de ese partido sostuvieron que un método apropiado para distribuir los escaños parlamentarios sería otorgar un cupo al subpacto de RN en cada circunscripción, y permitir que los subpactos de la UCC y la UDI negociaran para dividirse entre sí los restantes escaños, fórmula a la que se opusieron ambos partidos. En vista de la hegemonía electoral de RN, los candidatos de los otros dos partidos perderían si formaban duplas con candidatos de RN. De todos modos, RN también sabía que sin la UDI ni la UCC sus posibilidades de cruzar los umbrales electorales en todos los distritos se verían mermadas considerablemente con una derecha dividida. Por eso la UCC concentró sus energías en lograr que candidatos de Renovación Nacional se bajaran de determinadas listas para así permitir una competencia entre la UCC y la UDI. Francisco Javier Errázuriz, presidente de la UCC, se contactó directamente con líderes de Renovación Nacional para entablar negociaciones. Errázuriz argumentó que a la UCC se le debía "retribuir" por el 7\% que estaba aportando a la votación general de la derecha, y exigió que a su partido se le asignaran 11 circunscripciones en las cuales los candidatos de la UCC competirían sólo entre ellos. Los dirigentes de RN admitieron que la

\footnotetext{
32 Servicio Electoral de Chile.

${ }^{33}$ Actualmente Unión de Centro Centro Progresista.
} 
colectividad de Errázuriz tal vez tenía derecho a recibir esta cantidad de cupos, pero ciertamente no formando duplas en la combinación que él proponía. Resumiendo la lógica que prevalece para los partidos pequeños que forman duplas con otros más grandes, Errázuriz replicó: "No me den cupos, lo que quiero son escaños”34. A decir verdad, Errázuriz tenía razón. La UCC acabó consiguiendo 21 cupos. Con todo, los dirigentes de la UCC convencieron a los subpactos de RN y la UDI para que les cedieran ambos cupos en sólo tres circunscripciones. Los dos escaños que la UCC finalmente ganó fueron en estas circunscripciones. Los restantes 19 candidatos del partido cayeron derrotados.

Resulta evidente, entonces, que el tamaño relativo de los partidos y el apoyo que reciben determinan la importancia del compañero de lista. Si centramos nuestra atención en la derecha después de las elecciones de 1993 el panorama se aclara aun más. El decepcionante resultado de 3,2\% obtenido por la UCC en esos comicios, con victorias en sólo dos circunscripciones, le restó al partido gran parte de su fuerza como actor en las elecciones de 1997. En contraste, el subpacto de la UDI aumentó su porcentaje de la votación a 12,1\% en las elecciones de 1993 (pese a que el proceso de selección de candidatos lo perjudicó). Al mismo tiempo, la votación del subpacto de $\mathrm{RN}$ bajó al 16,1\%, con lo cual varió completamente la dinámica de las negociaciones, que se tornaron mucho menos complejas. El traspaso de un considerable porcentaje de la votación de RN a la UDI y la realidad de que ambos partidos estaban nariz a nariz en las encuestas dieron lugar a que en 1997 simplemente se repartieran los escaños en partes iguales entre sus dos subpactos. Ello fue posible porque la influencia que cada uno tenía en las negociaciones se igualó debido al nivel equilibrado de apoyo del que ambos gozaban a nivel nacional.

El proceso de selección de candidatos se volvió mucho más sencillo y directo el año 2001. El espectacular crecimiento de la popularidad de la UDI transformó la dinámica de las negociaciones, y este partido asumió un papel igualitario en la Alianza, que le permitió exigir una cuota de candidatos similar a la de RN. Más aun, en parte como resultado de la negativa experiencia con la UCC en 1989 y 1993, los dos partidos acordaron no negociar con colectividades más pequeñas de tendencia conservadora en las elecciones de 1997 y 2001. La norma que se ha ido imponiendo gradualmente para las negociaciones entre estos partidos ha sido la de repartirse los cupos igualitariamente entre ambos, realizando ajustes cuando se presentan casos de titularidad en el cargo y competitividad con la Concertación.

${ }^{34}$ Entrevista con Andrés Allamand, 13 de julio de 1998, Washington, DC. 
Esta dinámica no está limitada a la derecha. Al interior de la Concertación se ha producido un equilibrio similar en el respaldo para los subpactos de la izquierda y el centro, lo cual ha simplificado enormemente las negociaciones para las elecciones de 1997. Mientras en las primeras elecciones posteriores al régimen autoritario la democracia cristiana superó por un amplio margen a la izquierda, la distancia entre ambos sectores se ha ido estrechando progresivamente; así, en las elecciones de 1993 las fuerzas de la izquierda combinadas reunieron el 23,7\% y los democratacristianos el 22,3\%. En 1997 las negociaciones se vieron facilitadas por la cercanía en el nivel de apoyo recibido por ambos subpactos, de modo que se llegó a un acuerdo en términos generales a fin de repartir las candidaturas. Para la designación de candidatos en 2001, los subpactos de la izquierda y del centro estaban separados sólo por 1,5\% de la votación recibida en las elecciones de 1997, y esta proximidad en cuanto al nivel de respaldo condujo a la simple división de los escaños entre los subpactos. Ello se vio facilitado por la incorporación del PRSD en el subpacto de la izquierda, con lo cual la inscripción de sus candidatos se transformó ahora en preocupación del subpacto de la izquierda y no de la Concertación en general, la que en ocasiones anteriores había tenido que negociar la inscripción de los candidatos de dicho partido. Los democratacristianos ya no sintieron la necesidad de renunciar a un escaño en favor del PRSD, por lo que la inscripción de los candidatos de los partidos se redujo aproximadamente a una lucha entre el PS y el PPD para determinar quién cedería escaños para así hacerle lugar al nuevo socio del subpacto en la coalición. Navia tiene razón cuando observa que en las elecciones de 2001 las negociaciones al interior de la Concertación experimentaron un cambio gradual: desde negociaciones entre el PDC y el subpacto PS-PPD, hacia negociaciones entre el PS y el PPD ${ }^{35}$.

\section{Conclusiones y perspectivas sobre la selección de candidatos en Latinoamérica}

En este artículo se ha mostrado que el sistema electoral binominal ayuda a generar un proceso de selección de candidatos basado en diversas combinaciones de incentivos superpuestos, complejos y a menudo contradictorios. Las directivas de los partidos intentan asegurar el éxito electoral de su agrupación política, y al mismo tiempo garantizar la cohesión de las coaliciones que resulta indispensable en el sistema binominal, y que es también esencial para el éxito de cada partido.

${ }^{35}$ Navia: "Legislative Candidate Selection in Chile”, 2004, p. 18. 
En el artículo también se plantean algunas paradojas de la competencia y se proporcionan percepciones teóricas sobre la conexión entre sistemas electorales y procesos de selección de candidatos. A nivel de competencia individual la paradoja más obvia es que los candidatos con el potencial de recibir la mayor votación frecuentemente no son inscritos en las listas electorales, pues a veces son desplazados por un candidato de un partido menor en aras de la unidad de la coalición. En una situación que resulta aun más paradójica, al ceder candidaturas (y por ende, en último término, escaños) para pagar otros costos de mantención de la coalición, un candidato fuerte puede ser reemplazado por un candidato más débil de un partido menor (aunque ciertamente los partidos pueden decidir presentar candidatos más poderosos en alguna otra circunscripción). No menos paradójico se considera el hecho de que los resultados previstos de los candidatos sean potencialmente tan distintos según quién les toque como compañero en la lista de la coalición. Desean competir en una circunscripción junto a un candidato muy poderoso o bien junto a uno muy débil. Obviamente que escoger a los dos candidatos más fuertes maximizaría la votación de la coalición, pero determinados candidatos y subpactos a veces tienen un poderoso incentivo para recomendar la selección de un compañero de lista débil.

A nivel de coaliciones existen también realidades que llevan a escoger a candidatos que potencialmente no son quienes obtendrían la mayor votación. Como ya se ha señalado, es probable que los partidos más grandes estén dispuestos a ceder escaños en ciertas circunscripciones (donde el partido más poderoso podría tener una victoria asegurada) y así proporcionar a las colectividades más pequeñas un incentivo para incorporarse en la coalición y permanecer en ella. Por tanto, en ocasiones la coalición puede también acabar recibiendo menos sufragios en una determinada circunscripción que los que habría conseguido con una fórmula distinta de candidatos (por ejemplo, dos candidatos de grandes partidos ancla). Un partido capaz de reunir el 7\% de la votación nacional puede parecer atractivo como socio de coalición en cuanto a maximizar la votación global de la lista en todas las circunscripciones a nivel nacional. No obstante, resulta improbable que los candidatos de partidos con este nivel de respaldo gocen de una popularidad espectacular, por lo que su contribución para atraer más votos a una circunscripción individual será mínima. Aun así, una lista puede sacrificar el cupo y cedérselo al candidato del partido pequeño para así contar con un elemento adicional de apoyo nacional que les permita cruzar el umbral en otras circunscripciones. Ello sucede porque los partidos grandes también esperan obtener los votos de quienes apoyan a partidos pequeños en cir- 
cunscripciones donde éstos no han presentado un candidato. Lo anterior puede aumentar progresivamente la votación total de las listas en cada una de las circunscripciones, fenómeno que se traduciría potencialmente en una mayor cantidad de victorias para la coalición. Por ejemplo, el Partido Radical (y más tarde el PRSD) sólo ha recibido el 4\% de la votación en las elecciones legislativas. La Concertación le cedió cupos para que los votantes del PR sufragaran por candidatos de otros partidos de la Concertación en otras circunscripciones donde no compitieran candidatos del PR. En efecto, la Concertación "compró" un 4\% de apoyo nacional cediendo algunas candidaturas a los radicales. A su vez, cuando se multiplica en todas las circunscripciones, este respaldo nacional adicional pudo haber ayudado a aumentar la capacidad de la Concertación para traspasar los umbrales individuales en cada circunscripción individual. Al mismo tiempo, la Concertación evitó el surgimiento de una lista radical separada en todo el país, lo que le habría costado varias derrotas o habría impedido que sus candidatos doblaran en algunas circunscripciones.

Es más, dadas las normas esbozadas anteriormente, ocurre con bastante frecuencia que dos partidos menores de una coalición sean inscritos en una misma lista para competir entre sí, ya que ambos resisten la competencia con un partido ancla poderoso. Los partidos más pequeños, o partidos con menor votación, exigirán formar listas con dos candidatos de sus propias filas, o formar duplas con partidos menores como precio por unirse a una coalición. Así pues, cabe la posibilidad de que en estas circunscripciones la votación general de las listas sea mucho menor que la que se hubiera conseguido si se hubieran presentado dos candidatos de partidos poderosos. Pero, una vez más, éste es el precio que la coalición está dispuesta a pagar por mantener la unidad.

Desde una perspectiva teórica, en este artículo se presentan hipótesis sugerentes de las dinámicas de la competencia electoral y de los incentivos que inciden en los procesos de selección de candidatos en algunos tipos de sistemas electorales. Aun cuando la adopción de un sistema binominal resulta improbable en otros países, el caso chileno proporciona hipótesis teóricas más amplias respecto a la manera en que sistemas electorales estratégicamente complejos inciden en los procesos de selección de candidatos y en las elecciones. El análisis permite sustentar un argumento normativo en contra de los sistemas electorales estratégicamente complejos en cuanto a su capacidad representativa.

En primer lugar, muestra que los sistemas electorales estratégicamente complejos pueden producir resultados potencialmente negativos y con- 
trarios a la intuición. Las directivas de los partidos suelen tener incentivos para elaborar listas electorales que tal vez no incluyan a los candidatos más populares. A su vez, los votantes se enfrentan con un sistema impredecible, dudando de si su sufragio contribuirá a la elección de su candidato preferido o del compañero de lista de éste. En esencia, la complejidad del sistema aumenta la probabilidad de que se cometan errores estratégicos en la composición de las listas y en la votación, con consecuencias potencialmente frustrantes para los dirigentes de los partidos, los candidatos y los electores.

En segundo lugar, este caso muestra que los sistemas estratégicamente complejos pueden militar en contra de la democratización de los procesos de selección de candidatos, es decir, en contra de la introducción de elecciones primarias o de otros métodos que permitan asegurarse de que distintos sectores del partido y sus bases hagan oír su voz. El imperativo de equilibrar tan delicadamente los intereses de los votantes y de los partidos con el objetivo marco de las coaliciones de maximizar la cantidad de escaños dificulta la introducción de este tipo de cambios democratizadores.

En tercer lugar, este caso sugiere que los sistemas electorales estratégicamente complejos dependen de la informalidad para funcionar. Queda la duda de cuán sustentables son los procesos informales, los que en caso de fracasar pueden conducir a resultados muy indeseables ${ }^{36}$.

Por último, estas tres realidades combinadas generan una cuarta consecuencia no intencional. En lugar de proporcionar transparencia y apertura, la impredictibilidad de los sistemas estratégicamente complejos, y los procesos de selección de candidatos manejados por las directivas que aquellos pueden originar, reducen la legitimidad del sistema electoral y de la política democrática en general. Los votantes perciben que la victoria definitiva en las elecciones es el resultado de las maquinaciones de las directivas de los partidos, y no una expresión de la voluntad de la gente.

La reforma electoral se está extendiendo a paso acelerado por toda Latinoamérica. Si bien los especialistas han analizado las consecuencias de este fenómeno para los sistemas de partidos, pocos se han preocupado de cuál es el potencial de la reforma electoral para transformar el proceso de selección de candidatos. Desde la perspectiva más amplia en este artículo se ha demostrado que la reforma electoral probablemente transformará, de una manera que tiene directa relación con la capacidad representativa de la democracia, las prácticas tradicionales para escoger candidatos. En conse-

${ }^{36}$ Sobre la impredictibilidad y potencial inestabilidad del sistema véase Siavelis y Arturo Valenzuela: "Electoral Engineering and Democratic Stability: The Legacy of Authoritarian Rule in Chile”, 1996. 
cuencia, la democratización de los sistemas políticos de Latinoamérica depende no sólo de la estructura de los sistemas de partidos que está determinada por distintos métodos electorales, sino además de los incentivos para la selección de candidatos que aquéllos contribuyen a generar.

\section{REFERENCIAS BIBLIOGRÁFICAS}

Auth, José: “Elecciones Presidenciales y Parlamentarias de 1993”. En Estudios Públicos, 54 (otoño 1994).

Cox, Gary: "Electoral Equilibrium in Double Member Districts". En Public Choice, 44 (1984).

Downs, Anthony: An Economic Theory of Democracy. Nueva York: Harper Collins, 1957.

El Mercurio: 11 de junio de 1989, p. D4.

El Mercurio: 21 de mayo de 1989, p. C5.

El Mercurio: 17 de febrero de 1993, p. C5.

El Mercurio: "Consejo General de RN rechaza pacto con UCC”, 23 de mayo de 1993.

El Mercurio: "Piñera al Borde del Sí”, 30 de marzo de 1997.

Gallagher, Michael: "Introduction”. En Michael Gallagher y Michael Marsh (eds.), Candidate Selection in Comparative Perspective. Londres: Sage, 1988.

Guzmán, Eugenio: "Reflexiones sobre el Sistema Binominal”. En Estudios Públicos, 51 (invierno 1993).

La Época: 22 de junio de 1989.

La Segunda: "Las Corrientes Ocultas tras las Negociaciones". La Segunda, 19 de febrero de 1993, p. 13.

Magar, Eric; Marc Rosenblum y David Samuels: “On the Absence of Centripetal Incentives in Double Member Districts: The Case of Chile”. En Comparative Political Studies, 31 (diciembre de 1998).

Mainwaring, Scott y Timothy Scully: “Introduction”. En Scott Mainwaring y Timothy Scully (eds.), Building Democratic Institutions: Party Systems in Latin America. Stanford: Stanford U.P., 1985.

Ministerio del Interior: sitio "Elecciones históricas”, http://www.elecciones.gov.cl/

Navia, Patricio: "Legislative Candidate Selection in Chile". Trabajo presentado durante la conferencia "Pathways to Power: Political Recruitment and Democracy in Latin America”, Graylyn International Conference Center Wake Forest University, Winston-Salem, NC. 3 y 4 de abril de 2004.

Pastor, Daniel: “Origins of the Chilean Binominal Electoral System”. En Revista de Ciencia Política, 24:1 (2004).

Rabkin, Rhoda: "Redemocratization, Electoral Engineering, and Party Strategies in Chile, 1989-1995”. En Comparative Political Studies, 29 (junio de 1996).

Siavelis, Peter y Arturo Valenzuela: "Electoral Engineering and Democratic Stability: The Legacy of Authoritarian Rule en Chile”. En Arend Lijphart y Carlos Waisman (eds.), Institutional Design in New Democracies: Eastern Europe and Latin America. Boulder: Westview Press, 1996. 
Siavelis, Peter: "Continuity and Change in the Chilean Party System: On the Transformational Effects of Electoral Reform”. En Comparative Political Studies, 30 (diciembre de 1997).

Taagepera, Rein: "The Effect Of District Magnitude and Properties Of Two Seat Districts”. En Arend Lijphart y Bernard Grofman (eds.), Choosing an Electoral System. Nueva York: Praeger, 1984.

Valenzuela, J. Samuel y Timothy Scully: "Electoral Choices and the Party System in Chile: Continuities and Changes at the Recovery of Democracy". En Comparative Politics, 29 (julio de 1997). 